\title{
Learning, changing and doing - Critical citizenship through ecumenical exposure
}

\author{
Nell, Ian \\ Stellenbosch University \\ ianell@sun.ac.za
}

\begin{abstract}
Critical citizenship is becoming a very significant part of the educational pedagogy at Stellenbosch University relating to the vocational, personal and civic lives of the students and lecturers, focusing on critical and reflective thinking in what to learn, believe and do. Making use of the central concepts of critical citizenship as hermeneutical lenses, the main research question of this article is: "Does the exposure through ecumenical tours, as part of the programme in the Postgraduate Diploma in Theology in Christian Ministry, foster critical citizenship, and if so, in what ways?" The purpose of the article is therefore to take a closer look at one component of this specific programme and to see if, and in what ways, critical citizenship is embedded and fostered through aspects of ecumenical exposure. Factors at play in ecumenical exposure include the diversity of the student population, the content of the programme and, especially, the participatory and reflective practices of living faith communities. A pedagogical framework will be used to evaluate whether critical citizenship is enhanced through the ecumenical exposure of the programme.
\end{abstract}

\section{Keywords}

Critical citizenship, graduate attributes, cumenical exposure, pedagogy, profile for students

\section{Introduction}

The Faculty of Theology at Stellenbosch University participated in a project on critical citizenship between 2012 and 2013. ${ }^{1}$ As part of the project,

1 Like so many other concepts in scholarly work, a notion such as citizenship is not without its problems when it comes to clarity of meaning and semantics. Isin and Turner (2002:4) describe it in the following way: "The modern conception of citizenship as merely a status held under the authority of a state has been contested and broadened 
an interdisciplinary group conducted qualitative empirical research through focus group interviews. ${ }^{2}$ A number of lecturers and students were identified and semi-structured interviews were held in two focus group meetings concerning the respondents' perceptions of critical citizenship, and the ways in which and places where they see the notion operative in the programmes and curricula of the Faculty. ${ }^{3}$ The data of the research provide interesting perspectives on the contested nature of the notion, as is apparent from the following two quotes from a lecturer and a stude

Critical citizenship would imply a certain critical loyalty. There seems to be a change in our thinking about citizenship that it is about more than just obedience, it's about the ability to have a critical dialogue with your perceptions of society. (Theology lecturer)

I am critical about the word 'citizenship'. It is a nationalist concept that does not necessarily agree with my convictions ... I think it is a very Western term and to apply that to South Africa would be a challenge. Citizenship is more Western, more our way of doing things, and one cannot apply that to other cultures. ${ }^{4}$ (Theology student)

In the meantime, the Faculty also became involved in the project on graduate attributes, as part of an initiative related to signature learning that started in 2011. It is a project that was initiated by the Centre for

to include various political and social struggles of recognition and redistribution as instances of claim-making, and hence, by extension, of citizenship".

2 For a full report on the project, see Costandius et al. (2015:545-558).

3 The question that guided the initial phase of research was "What are the common perceptions of students and staff of critical citizenship, and what conditions are believed to successfully foster critical citizenship at Stellenbosch University?" Four focus group discussions with a group of lecturers, and four focus group discussions with students (both with up to eight participants) were held with four different departments (Theology, Visual Arts, Chemistry and Agri Sciences) [two of these are faculties, not departments] to discuss the notion of critical citizenship and its implications for the social role of the respective departments. Existing practices that draw from critical citizenship principles were discussed (also with students who have participated in critical citizenship-influenced teaching methods), as more open discussions were held about the relationship between the University and the community, the expectations of graduates, and the expectations of lecturers in terms of their investment in teaching.

4 Some quotations were translated into English where the original interview was conducted in Afrikaans. 
Teaching and Learning, and was part of the strategic initiatives of the University in the planning cycle for 2013-2018. ${ }^{5}$ After three workshops during 2013, in which representatives from all eleven faculties at the University participated, it was decided that the graduate attributes should be embedded in the programmes and modules of all the different faculties. At the Faculty of Theology, the decision was to use the Master of Divinity (MDiv) ${ }^{6}$ for this purpose. Already at the end of 2013, the first workshop was held at the Faculty of Theology to plan for this embedment, and during the course of 2014, two workshops were held with all the lecturers involved in the programme to work on the implementation of the graduate attributes in the different modules of the course.

Concerning the graduate attributes, a University circular letter on the initiative describes them in the following way: an enquiring mind, an engaged citizen, a dynamic professional and a well-rounded individual. It is specifically the first two attributes ${ }^{7}$ that have a direct connection with

5 This is known as the Stellenbosch University Institutional Intent and Strategy 2013-2018 and described in the following way: "This Institutional Intent and Strategy 2013-2018 takes cognisance of and supports the proposed outcomes of the global development goals and the National Development Plan of South Africa. The country will be a better place if we tackle the challenges of the $21^{\text {st }}$ century in the spirit of 'making hope happen'. The University's commitment to serving society has since 2007 found expression in the HOPE Project, and 'creating hope' has been recognised as the institution's footprint in South Africa, on the continent of Africa and internationally" (Stellenbosch University, year, p 11).

6 In the 2015 Yearbook of the Faculty the programme is described in the following way: "The MDiv in Church ministry offers training to ministers, clergy, pastors, lay workers, pastoral care givers and pastoral therapists for the ministry. The programme is designed to equip people professionally for the ministry" (p 32)

7 These two attributes are described in the following way:

"An enquiring mind: A graduate who can be described as having an 'enquiring mind' is curious, a lifelong learner who thinks critically and creatively, and someone who uses systematic methods of enquiry to formulate decisions. An enquiring mind is open to new as well as diverse ideas, is willing to learn from the received wisdom of the past, as well as to invent new ways of knowing and doing. This involves taking the best from international and dominant ways of knowing, and in addition from indigenous, local, lay and underrepresented knowledge sources. It involves seeing the interconnectedness of different knowledge sources and knowledge systems, and being able to process ideas and information in multi-disciplinary teams. An enquiring mind exercises discernment with regard to knowledge sources, knowledge claims and the values of knowledge. He or she considers the responsibility and accountability that accompany knowing and learning, and the respect for research-oriented approaches to problem solving. 
the topic of this article. As mentioned above, both critical citizenship and graduate attributes relate to Stellenbosch University's "HOPE Project" (see footnote 7). According to the late rector of the University, Prof Russel Botman, Stellenbosch University wants to be a multiracial university working with pedagogy of hope, aiming at an Afrocentric approach to higher education.

The purpose of this article is therefore to examine the role and importance of critical citizenship within a specific postgraduate programme $e^{8}$ housed at the Faculty of Theology, with the ecumenical tour, which is part of the programme, as a very particular case study in point.

The basic research questions of the investigation can thus be stated in the following way: "Does the exposure through ecumenical tours, as part of the programme in the Postgraduate Diploma in Theology in Christian Ministry, foster critical citizenship, and if so, in what ways?"

To answer this question, the article takes the following route: Firstly, it is important to get more clarification on some of the concepts and terminology that will be used in the study. Secondly, instead of trying to cover the whole programme of the postgraduate diploma, the focus will only be on one aspect, and that is, on the ecumenical tours. Thirdly, the historical development of these tours will then be briefly discussed. Fourthly, some concepts as hermeneutical lenses will be used to look at the different activities taking place during these tours. The purpose of this

An engaged citizen: An engaged citizen is one who is able to exercise leadership, and one who understands how to contribute as a member of a team and community, thus to collaborate and be of service. An engaged citizen cares for him or herself and exercises care for others in increasingly widening concentric circles. This implies, for example, care in the family setting, the workplace or the classroom, at a municipal or regional level, at the national, continental as well as international level. Citizenship implies an awareness of a relationship between commitment to the local and national polity, on the one hand, and an awareness of the dangers of various forms of exclusivity, on the other. A Stellenbosch University graduate should have had the opportunity to engage critically in community interaction in the region, and to have considered potential solutions to the crises of sustainability and climate change. A SU graduate will be aware of the value of interaction on a global level, and be open to influences from international settings. An engaged citizen has been exposed to the idea that transformation of society involves transformation of the self."

8 The Postgraduate Diploma in Theology in Christian Ministry is a programme for students who want to be legitimised as ministers in the Reformed tradition. 
exercise is to try to determine whether these tours do indeed foster critical citizenshi Lastly, the activities that have been identified in this way will be scrutinised with concepts from the field of leadership studies, specifically making use of the model of Bell (2010), in order to give a final answer to the research question.

\section{Terminological clarification}

The working definition for "critical citizenship" used by the group that did the initial research is as follows:

Critical citizenship is based on the promotion of a common set of shared values such as tolerance, diversity, human rights and democracy. As an educational pedagogy, it encourages critical reflection on the past and the imagining of a possible future shaped by social justice, in order to prepare people to live together in harmony in diverse societies (adapted from Johnson \& Morris, 2010:77-78).

Three of the key concepts that emerge from the definition are: a common set of shared values, an educational pedagogy and imagining a possible future shaped by social justice.

A common set of shared values: A common set of shared values is of central importance, especially when it relates to the development of a curriculum in an academic programme. Some of these values include tolerance, diversity, human rights and a liberal democracy (Swartz, 2006, $552)$. Waghid $(2004,525)$ adds to this emotional maturity and compassion with the circumstances of people as another two important values. Within theological discourses there are three values that could be seen as belonging to the heart of the conversation concerning values, namely unity, reconciliation and justice. These three concepts are also central to the socalled Belhar Confession of the Uniting Reformed Church in South Africa (Cloete \& Smit, 1984). Another very important value that functions as a basic assumption on the ecumenical tours is the fact that society is unequal and the students exposed to these inequalities do want to see positive social change. 
An educational pedagogy: The choice of a pedagogy for teaching and learning is of central importance, not only in relation to critical reflection, but also concerning the teaching and learning outcomes and the activities involved. A critical pedagogy, working with the epistemological assumption of a pedagogy of hope, ${ }^{9}$ asks the question: "What are the pedagogical claims that a liberal democracy is putting forth as a challenge to the curriculum and in what ways can it contribute to a pedagogy of hope for transformation?" Part of this is a very strong focus on multiculturality, enjoying considerable attention in the policy documents of Stellenbosch University.

Imagining a possible future shaped by social justice: Imaginatively creating an alternative possible future is very important in theological discourses, and linking it with social justice issues give these discourses a very specific focus. The decision of Stellenbosch University for a pedagogy of hope also operates with the notion of an imaginative alternative for the future. ${ }^{10}$ The important element of justice becomes the focus when Botman (2013:2) emphasised that it is specifically the poor, vulnerable and marginalised people that need a pedagogy of hope to unlock an alternative future. The purpose of all of this is "to prepare people to live together in harmony in diverse societies" (Johnson \& Morris 2010:78).

\section{The history of the ecumenical tours}

In his chapter titled "Unlikely, but daring pioneers: On the Stellenbosch ecumenical tours from 1984-1991”, Anthonissen (2013:372-384) reflects

9 The concept of a pedagogy of hope was coined by Paulo Freire, well-known Brazilian scholar in education, who became known for his theory on education published in a book entitled Pedagogy of the oppressed (Freire, 2014b). During the years of apartheid, this book was banned in South Africa. It was then illegal to ask the question about the learning needs of the oppressed. Freire's follow-up publication had the title Pedagogy of hope: Reliving pedagogy of the oppressed (Freire, 2014a), published in 1994, and contained the seeds of a new philosophy of education. He asked himself what are the pedagogical conditions within a democracy and what does a curriculum look like in this situation. He developed his ideas within the context of Brazil. His answer was that poor and marginalised people experiencing oppression need a pedagogy of hope. The same applies to the South African situation, because all of us have been influenced by our democracy, but the pedagogical meaning of the changes since 1994 still requires further reflection in higher education (Botman, 2007:3, summary and translation by I Nell).

10 Cf the work of Nussbaum (2002) working with the notion of "narrative imagination" and looking to enhance a deeper understanding of difference and diversity, allowing one to step into the shoes of another person. 
on the role that these tours played in the lives of a number of students since the first tour back in 1984. If one keeps in mind that the tours took place during the last years of apartheid, and one reads about the people and places they visited, one can understand why the author refers to these students as daring pioneers without them thinking about themselves in this way. What is, however, significant for this article is to see what one finds from the experiences and reflections of these students when one looks through the lenses identified in the previous section.

Through the lenses of a common set of shared values, there was a specific need among the group for "crossing boundaries, moving into new territory, discovering and exploring a political, social and ecumenical landscape that the leadership of the Dutch Reformed Church had abandoned 24 years earlier" (Anthonissen 2013:373). It was especially the concern of these students that they had to enter the job market after their studies, but that it was a place marked by escalating tendencies of estrangement (Anthonissen 2013:373). Anthonissen (2013:373) summarises the essence of this set of values in the following way: "Not only did they break through the selfimposed isolation of the majority of white Afrikaners [...] but they were also willing to be exposed to another South African reality of the 1980s".

From the above it becomes clear that notions such as transgressing borders, moving into new spaces, discovering and exploring a new landscape and especially being exposed to a different South African reality were at the heart of this common set of shared values. It was, however, not only the exposure to the variety of different contexts that formed part of these shared values, but also the "ecumenical composure" of the groups themselves. The organisers made a concerted effort concerning the diversity of the group, specifically ensuring that there was considerable ethnic diversity among the group on each of these tours. The exposure experienced and the interaction among these students from such different cultural and socio-economic backgrounds, often developing into friendships, made a huge impact on the lives of these students and also on their later years in ministry.

Through the lens of an educational pedagogy it was clear that the exposure of the students during the tours often confronted them with "a reality which was dark and deeply disturbing, at times shocking, but if you opened up yourself to it with honesty, it was also exciting, challenging and full of hope" (Anthonissen 2013:373). This reality asks for critical reflection, 
and therefore, an important part of these tours was to create a space for these kinds of reflections, and to facilitate the conversations from different viewpoints. During these sessions the students had the opportunity to share their impressions and experiences and to evaluate what they learned. These critical reflections were not only a good learning process, but were also used to prepare the students for the home-coming, which was often not easy because of what had been experienced (Anthonissen 2013:379-380).

Through the lens of imagining a possible future shaped by justice it comes as no surprise that the students gained significant first-hand experience about the political and social circumstances, especially related to issues of social justice. The comments that follow serve as an illustration (Anthonissen 2013:380):

- They discovered the dangerous and often misleading power of perceptions and how perceptions, gained second-hand, can strengthen and enforce enemy images which do not always accord with reality;

- They learnt that, due to indoctrination and social conditioning, what they had taken to be normal, was often viewed by others as a totally abnormal state of affairs;

- They discovered that the majority of blacks in the country did not hate their white oppressors, but were extremely gracious, hospitable and forgiving. Just a small sign of interest or of reaching out would almost immediately draw a smile and remove boundaries. They discovered this is the real and continuing miracle of South Africa.

By making use of the three heuristic lenses it becomes clear that the different aspects relating to critical citizenship are in interaction with one another. Looking at it from this perspective, critical citizenship connects, on the one hand, with the critical thought processes in terms of what and who to believe and ways to act; and on the other hand, with the critical engagement of society and communities who were the victims of a specific political dispensation. This also underlines the importance of a critical pedagogy of which the following characteristics are identified by Johnson and Morris (2010:81-84): a) an emphasis on the political and ideological dimension of knowledge production; b) a focus on the collective; $c$ ) a focus on understanding subjectivity in critical thinking; and d) an emphasis on 
praxis. For Paulo Freire (2014a) the project of a critical pedagogy centres on deconstruction and the breaking down of structural power imbalances through critique and analysis.

In this section, the researcher made an effort to explain the origins of the ecumenical tours exactly 30 years ago by making use of a set of heuristic lenses. The purpose was to focus on some features that filled critical citizenship with a specific content. The next phase of the article entails looking at the current situation of these tours within the specific programme. The researcher has been the co-ordinator of the Postgraduate Diploma in Theology in Christian Ministry for the past five years and regards the ecumenical tours as an important component of the programme, especially concerning the development of critical citizenshi

\section{Components of the PGD programme}

In the Yearbook of the Faculty of Theology (2015:29) the target group of the programme is described in the following way: "The programme aims to provide supervised practical training for prospective ministers with a view to integrating theological theories with ministry practice, and developing ministry skills within a specific denominational context". Concerning the content of the programme, the following is stated: "The content is aimed at the requirements of ministry and the development of ministers, Christian leaders and pastoral care givers. The programme is aimed at exposure to and preparation for congregational ministry and the development of ministry skills" (2015:30). In further describing the content of the programme, the following reference is made concerning the ecumenical tours: "In June, after the half-year assessment, all the candidates take part in a compulsory combined ecumenical tour of approximately two weeks" $(2015,31)$.

Many things happened in the 30 years since the first tour took place. Not only did we find ourselves in a new liberal democracy after 1994, but also waves of globalisation, individualisation and a consumer culture broke over the people of South Africa, leaving many people fraught with uncertainties. Smit (2008:92) even speaks about a "collapse into modernity" that we have experienced in our country. 
In spite of these dramatic changes in our country, trustworthy research, such as the work done by the Institute for Justice and Reconciliation (IJR), making use of a reconciliation barometer (2011), ${ }^{11}$ provides enough evidence to show that there are still huge gaps concerning social cohesion among the different cultural and ethnic groups of the country. The need for exposure to and experience of the many diverse contexts of communities, and especially the many different forms of inequality, did indeed escalate. In no way can the harmonic living together of the different groups in our country be taken for granted. Some of the more pessimistic commentators are of the opinion that we are in a worse position than before 1994.

The type of "lived experience" that forms an important component of the ecumenical tours includes a variety of activities and exposure. ${ }^{12}$ The researcher, as co-ordinator of the tours during the past five years, has tried to organise each of the tours in a different region of the country. Some of the activities on the tours and places visited include the following:

- The students attend the worship services of different denominations that vary from their own denominational background. Given the fact that most of these students are from a Reformed background, they are exposed to the practices and activities of the Roman Catholic and Eastern Orthodox traditions.

- There is also the opportunity for conversations with the spiritual leaders of these traditions, creating the opportunity to get an "insider perspective" on the tradition. During the 2014 tour, the group stayed in a Roman Catholic monastery and retreat centre close to Windhoek in Namibia, and experienced some of the faith disciplines of the community and listened to the story of a priest who served for 50 years as a missionary from Germany.

11 The South African Reconciliation Barometer (SARB) survey is a nationally representative public opinion poll conducted annually by the IJR, which focuses on progress in reconciliation in South Africa. The SARB measures progress in reconciliation through six complex hypotheses and indicators, namely political culture, human security, crosscutting political relationships, dialogue, race relations and historical confrontation. In other words, the barometer aims to deduce how the above-mentioned aspects influence reconciliation in South Africa. It is a joint project of the IJR and the Khayabus opinion poll of Ipsos-Markinor, which collects data through interviews with a nationally representative sample of more or less 3500 South Africans.

12 See in this regard the work of Ganzevoort (2009). 
- Conversations are also organised with people involved in broader ecumenical structures, such as the chairperson of the Namibia Council of Churches, rectors of centres and colleges responsible for theological education, and moderators and personnel of synodical bodies from the different denominations.

- During the recent tours, we also paid visits to non-governmental organisations, such as the Christian Medical Relief Centre and Bethesda Hospital in George, where they care for children orphaned by HIV/Aids as well as people who are terminally ill. We visited projects assisting with job creation in Port Elizabeth, such as Vista Rus, a factory producing tinned fish in Mossel Bay to better understand the circumstances of the manual labourers, a soup kitchen in Tembalethu township close to George to realise the need and vulnerability of the inhabitants, and many more.

- By visiting these organisations and through exposure to their activities the students also experience something of their living and working conditions, especially of people living in squatter camps and informal housing. It is normally in these circumstances that the students become deeply aware of the inequalities of our society.

Apart from the 'ecumenical contexts' that the groups visited, one also has to take the 'ecumenical composure' of the groups into account. Students from many different denominational (mostly Reformed), social and cultural contexts form part of the groups. For almost two weeks, these students are continuously in one another's presence and it is interesting to note the many different interactions taking place among the students. Conflict is not excluded and the facilitation of these kinds of contestations poses its own challenges.

The ecumenical tours form an important component of the Postgraduate Diploma in Theology in Christian Ministry, and therefore, the researcher takes a closer look in the next section at the processes contributing towards the nurturing of critical citizenship education. 


\section{Processes facilitating critical citizenship education}

With the heuristic lenses of a common set of shared values, educational pedagogy and imagining a possible future shaped by social justice as epistemic points of departure, considerable planning and organisation goes into these tours. The researcher is convinced that critical citizenship, as a combination of reflective thinking and critical engagement in social contexts, is nurtured through the following processes:

- Exposure to and training for congregational ministry: Exposure to different contexts in research literature relates to "experiential knowledge" and is described as: "Information and wisdom gained from lived experience and understanding things and events through direct engagement. Lived experience incorporates the actual experience itself along with the meanings attributed to the experience by the person experiencing it" (Given, 2008, 322). It is exactly this exposure in which the students participate during these tours that create the ideal conditions for teaching and learning with regard to congregational ministry. The direct engagement and listening to the narratives of individuals and the activities of groups in faith communities create ideal teaching and learning opportunities.

- The integration of theories in theology and ministerial practice: In the light of the 'lived experience' and the agreed-upon values of tolerance, diversity and empathy, the students get the opportunity to reflect on their experiences critically at the end of each day. By creating a space to share experiences and perceptions, the students have the chance to start a critical dialogue between what they have learned during the course of five years in classroom settings and the practices that they observed during the activities of the day. "Reasonable reflexive thinking on deciding what to do or believe" (Johnson \& Morris, 2010, 77) therefore forms the heart of this pedagogical process and often leads to the transformation of the thought processes of the students. Within the field of practical theology, the praxis-theory interaction is one of the basic points of departure in the field of study.

- Developing ministerial skills: In the profile for students entering ministry that is normally provided by the formal partners 
(denominational bodies) of the different churches, one finds the following skills related to ministerial competencies: proclamation and liturgical skills, communication and teaching skills, pastoral skills, the ability to shape a community of faith, and diaconical involvement in the community and wider society through processes of reconciliation and justice. Although there is not an opportunity during the tour to practise these different skills by the students themselves, it is through the exposure to 'practitioners' and critical reflection that students are aided in the development of ministerial skills.

One could identify and describe other processes as well, but according to the researcher the latter description is sufficient to get some idea of the role that these factors play in the fostering of critical citizenshi In what follows, I will return to the research question and a final round of reflections will be undertaken by making use of a specific model for teaching and learning.

\section{Learning, changing and doing}

The research question were formulated as follows: "Does the exposure through ecumenical tours, as part of the programme in the Postgraduate Diploma in Theology in Christian Ministry, foster critical citizenship, and if so, in what ways?" By making use of the model of Bell (2010) with the key concepts of "learning, changing and doing", the researcher will undertake not only to answer the 'if' of the research question, but again revisit the "in what ways" it is related to critical citizenship education.

Bell (2010:93) investigates the development of leaders in religious and non-religious organisations who are open to the invitation for growth in their work. According to him, these are also the people that can facilitate positive transformation in their communities of practice. He undertakes to develop a transformation model for leadership, where the integration of learning, changing and doing helps the process. Transformation leadership can, therefore, be directly linked to critical citizenship education.

In the next phase, attention will be paid to each of these aspects and then related to the 'in what ways' of critical citizenship development during the ecumenical tours. According to Bell (2010:93), the result of using this model is people who grow as leaders, find meaning and purpose in 
their serving, and contribute in meaningful ways to the changes in their (religious) organisations. For him, the notion of transformation is of central importance and he is specifically interested in the possibilities of 'deep change' that takes place in people while they are busy doing their work. It is quite clear that it is all about an integrated process of learning, changing and doing that is systemically related to one another.

\subsection{Learning}

The learning of something new is often the point of initiation of bigger systemic changes and this is indeed also the case in theological learning processes. This assumption contributes in at least two ways to the development of transformational leadershi In the first place; it roots the development of leadership in universal experiences that have the capacity to transform culture and people. In the second place, it helps to understand the essence of leadership (Bell 2010:97).

The development of critical citizenship entails the capacity of students to learn to understand the cultures of people that differ from their own. From experience, we know how deeply our own lives are shaped by the culture through which we learned how to think and act. Bosch (1991:291292) helped us to understand "cultural vulnerability". He illustrated in his research how perspectives of Western and post-Enlightenment thinking developed language that witnessed of cultural superiority. Notions such as dark, suspicious and ignorant that were very often ascribed to non-Western cultures serve as propaganda for Western styles of living. Therefore, respect for culture is of utmost importance and one of the key values for the development of critical citizenship education that is nurtured on these ecumenical tours.

In the light of the afore-mentioned, it is imperative to think 'critically' about culture. Sometimes it might appear on the surface as though culture is neutral in its relationship to theology; however, one cannot ignore the fact that it relates on a very deep level to our worldview. It is also quite often, in this regard, that through interacting with the source documents of the Christian faith we are confronted with alternative cultures of the ancient people, resulting in our worldview being altered. 


\subsection{Changing}

The learning and understanding of new cultures often leads to the transformation of critical thinking of the students, and often develops new patterns of conduct. Effective learning from a psychological perspective results in the change of behaviour. In this regard, we have to remember that new patterns of behaviour are not an end in itself; it is more a case of new patterns of acting and thinking, witnessing to the fact that internal changes have taken place in an individual. This is all about the development of the character of the individual and also relates to the fourth graduate attribute, namely, a well-rounded individual.

Once again, one can see a direct link to the development of critical citizenshi Preparing students to become critical citizens does not, in the first place, depend on the education and coaching of students to act in a specific way, but on the transformation of the person. The development of certain capacities of students to fill their position in society is not the primary goal of theological education and training; these aspects contribute towards and flow forth as the result of the changes that already took place within the students. According to Grugulis $(2007,14)$, it often happens that this kind of "capacity thinking" in education relegates students to be mere individual characters, acting and performing certain tasks in isolation from specific communities, leaving little space for innovation and creativity.

In the stories Anthonissen (2013:383) writes about and previously referred to it is interesting to read how some of the students, looking back after some years in ministry, witness to the fact that their ministry took a different route because of the patterns of thought and alternative ways of looking at life, and especially issues of justice, that were shaped during these tours. They testify to the fact that these experiences resulted in changes in their acting and even believing. The example of Anthonissen (2013:383) himself witnesses to the fact that "[i]n no small way, my studies towards a PhD on the credibility of the church in the theology of Dietrich Bonhoeffer were sparked and inspired by the experiences I gained from the ecumenical tours and the questions they raised". 


\subsection{Doing}

In educational psychology there exists little doubt that emerging leaders learn new skills while they are busy performing and acting certain roles themselves. The value of experience in the processes of learning and changing can therefore not be underestimated. A critical element that relates to this is the capacity to accurately observe activities, to analyse and to compare them with previous experiences and to develop new knowledge through these processes. In the literature, this is quite often referred to as the "spiral of experience" (Bell 2010:104-105). Osmer (2008:4) speaks of a "spirituality of priestly presence" as a prerequisite for active listening.

Kaagan (1998:79-82) is of the opinion that one of the most efficient and cost-effective methods for the development of leadership capacities is to carefully structure opportunities for students to participate in peer groups reflecting on their experiences of a specific activity or event. For the development of critical citizenship on the ecumenical tours, this activity, that of peer group discussions, serves as a central point of departure. Although the students do not have to perform certain ministerial practices during the tour, it is the "examples of good practice" (Osmer 2008:185) that serve as a rich source for reflection. What is time and again surprising is the wide variety of interpretations of the same event during these peer group discussions. It is often precisely during these moments that the rich diversity of cultures and personal backgrounds play an important role in the process of interpretation. Apart from the fact that the students often have directly opposite experiences of the same event, it also creates the space and opportunity to listen emphatically to one another and to learn from cultures different from their own.

\section{Conclusion}

To answer the "if" and the "in what ways" of the research question concerning the development of critical citizenship; many more and different perspectives could be developed. However, the researcher is convinced that the integration of learning, changing and doing in terms of Bell's model (2010) is indeed of value to answer the question in a positive way and to affirm that critical citizenship education does indeed take place 
during these ecumenical tours. The researcher also undertook to describe in what ways critical citizenship relates to leadership development.

In the triad of learning, changing and doing, we also discover the key components of an integrated way in which we can go about answering the 'in what ways' of the research question in a positive way. The necessary attention to these aspects is, however, not a guarantee that the students will be sufficiently prepared and ready to live in harmony in diverse cultural contexts, but at least it is a step in the right direction.

What also became clear through the research is the conclusion that the research group made in their project on critical citizenship at Stellenbosch University, namely "We were of the opinion that, in order to promote deep and meaningful engagement with issues of social justice and foster a critical social conscience in both students and lecturers, the university needs to develop a quality, holistic education" (Bell 2010:111).

This remark about 'holistic education' is one of the points of departure for the Postgraduate Diploma in Theology in Christian Ministry at Stellenbosch University. This programme does not operate in isolation and should be evaluated in its relation to the MDiv and the undergraduate programme, so as to decide whether we can speak, in this case, of "holistic education". In light of this situation, the researcher recently undertook, in co-operation with the Unit for Innovation and Transformation as part of Ekklesia (a Centre for Ecumenical Theology) and linked to the Faculty of Theology, the development of a questionnaire. The aim of the project is to investigate the perceptions of alumni from the Faculty of Theology at Stellenbosch University concerning the different experiences during their years of study; inter alia, the development of components of critical citizenship and graduate attributes.

\section{Bibliography}

Anthonissen, C 2013. Unlikely, but daring pioneers: On the Stellenbosch ecumenical tours from 1984-1991. In M-A Plaatjies-Van Huffel \& R Vosloo (Eds.), Reformed churches in South Africa and the struggle for justice: Remembering 1960-1990. Stellenbosch: Sun Press. 372-384 
Bell, S 2010. Learning, changing, and doing: A model for transformational leadership development in religious and non-profit organizations. Journal of Religious Leadership, 9(1), 93-111.

Bosch, DJ 1991. Transforming mission: Paradigm shifts in theology of mission. New York: Orbis: Books.

Botman, HR 2007. 'n Multikulturele universiteit met 'n pedagogie van hoop uit Afrika: Inhuldigingstoespraak. [Online] www.sun.ac.za/university/ Management/rektor/toesprake.html

Botman, HR May 22, 2013. The role of universities in the development of Africa. Paper presented at ETH Zurich (the Swiss Federal Institute of Technology), Zurich.

Cloete, GD \& Smit, DJ 1984. 'n Oomblik van waarheid. Kaapstad; Tafelberg.

Costandius, E; Blackie, M; Leibowitz, B; Nell, I; Malgas, R; Rosochacki, SO \& Young, G 2015. Stumbling over the first hurdle? Exploring notions of critical citizenship. In M Davies \& R Barnett (Eds.). The Palgrave handbook of critical thinking in higher education. New York: Palgrave Macmillan. 545-558

Freire, 2014a. Pedagogy of hope: Reliving pedagogy of the oppressed. London: A\&C Black.

Freire, 2014b. Pedagogy of the oppressed: 30th anniversary edition. New York: Bloomsbury.

Ganzevoort, RR 2009. Forks in the Road when Tracing the Sacred. Pract. Theol. Hermeneutics Lived Relig. Address International Academy of Practical Theolology. August 3, 2009. 1-15

Given, LM (Ed.) 2008. The Sage Encyclopedia of Qualitative Research Methods. California, Thousand Oaks: Sage Publications.

Grugulis, I 2007. Skill, training and human resource development: A critical text. London: Palgrave Macmillan.

Hofmeyr, JH 2006. Report of the sixth round of the South African Reconciliation Barometer Survey. [Online] https://sabarometerblog.files. wordpress.com/2009/09/sa-reconciliation-barometer-sixth-round-report.pdf 
Isin, EF \& Turner, BS (Eds.) 2002. Handbook of citizenship studies. London: Sage.

Johnson, L \& Morris 2010. Towards a framework for critical citizenship education. The Curriculum Journal. 21(1):77-96.

Kaagan, SS 1998. Leadership development: The heart of the matter. International Journal for Educational Management. 12:74-81.

Nussbaum, M 2002. Education for citizenship in an era of global connection. Studies in Philosophy and Education. 21(4/5):289-303.

Osmer, RR 2008. Practical theology: An introduction. Grand Rapids, MI: Eerdmans.

Smit, DJ 2008. Mainline Protestantism in South Africa-and modernity? Tentative reflections for discussion. Dutch Reformed Theological Journal = Nederduitse Gereformeerde Teologiese Tydskrif. 49(1\&2):92-105.

Stellenbosch University Institutional Intent and Strategy 2013-2018.

Swartz, S 2006. A long walk to citizenship: Morality, justice and faith in the aftermath of apartheid. Journal for Moral Education. 35:551570.

Waghid, Y 2004. Compassion, citizenship and education in South Africa: An opportunity for transformation? International review of Education. 50:525-542.

Yearbook of the Faculty of Theology, Stellenbosch University. 